\title{
Influence of Mineral admixtures on Compressive strength of Ternary concrete with different Water binder ratios
}

\author{
Vijaya Bhaskar Reddy Suda ${ }^{1}$, P.Srinivasa Rao ${ }^{2}$ \\ Professor and Head, Dept of Civil Engineering, CMR Technical Campus, Hyderabad, T.S. India ${ }^{1}$ \\ Professor and Principal, Dept of Civil Engineering, J.N.T.U. College of Engineering.Hyderabad, T.S. India ${ }^{2}$
}

\begin{abstract}
The use of pozzolans such as Micro silica (MS), Ground Granulated Blast Furnace Slag (GGBS), Fly ash, Metakaolin, Rice husk ash etc. in cement concrete, individually as a mineral admixture (MA) has been studied widely. Information available is less, when both MS and GGBS together are present in blended concretes. Therefore the present study is directed towards developing a better understanding on the combined performance of MS and GGBS on the strength properties of Ternary concrete over an Ordinary concrete. An extensive experimentation was carried out to arrive at optimum level of MS and GGBS. Three controlled concrete mixtures and twelve ternary concrete mixtures were prepared for each water cement ratio i.e. $(0.55$, 0.45 , and 0.35) in three groups, according to their binder content. Ternary concretes were obtained by adding MS (5\%, 10\% and 15\%) and GGBS (20\% 30\% 40\% and 50\%) to the ordinary Portland cement. Compressive strength characteristic of ternary concrete (TC), for all the combinations were determined at 7, 28, and 90 days. Ternary concrete have exhibited good improvements on ordinary concrete. The experimental results showed that, the strength properties of Ternary concrete increases with increase in cement replacement level (CRL) of cement replacement materials (CRM) i.e. MS and GGBS. After an optimum point, at around $40 \%$ of the total binder content, the addition of $M S$ and GGBS does not improve the strength properties.
\end{abstract}

Keywords: Compressive strength, CRL, CRM, GGBS, Micro Silica, Ordinary Portland cement and Ternary concrete,

\section{Introduction}

In the recent past, good attempts have been made for the successful utilization of various industrial by products such as (fly ash, micro silica, rice husk ash, ggbs, and metakaolin.etc.) to save environmental pollution by reducing the utilization of cement, without compromising the present requirements of huge infrastructure like high-rise buildings, large span bridges, etc. Otherwise rapid production of cement is required to meet the huge demand and it leads to the release of hazardous gasses such as $\mathrm{CO}_{2}$ and $\mathrm{NH}_{4}$ in to the atmosphere which creates severe environmental problems. It has been reported that over $90 \%$ of carbon dioxide emissions from the concrete industry are attributable to Portland cement clinker production, and approximately one tonne of $\mathrm{CO}_{2}$ is generated for making one tonne of clinker (Malhotra, 2004).[1].The scarcity of natural raw material, depleting energy resources, problems of disposal of waste materials and global warming due to emission of green house gases are the long - term results of rapid industrialization. Every industry tries its best to combat and minimizes these global problems in concrete construction; the primary route is to reduce the content of ordinary Portland cement (OPC) in concrete. Micro silica (MS) and Ground Granulated Blast furnace Slag (GBS) are Mineral admixtures (MAs) which can utilize both heat and calcium hydroxide generated during hydration of cement. Because of these reason, they can become good cement replacement material (CRM), as recognized now in IS: 456-2000 (Rajamane, 2001: BIS, 2000) [2]. The engineering benefits from the use of mineral admixtures in concrete result partly from their particle size distribution characteristics, and partly from the pozzolanic and cementitious reactivity. When OPC is replaced by GGBS the rate of gain of strength of concrete is slower at early age, and this limits its use in concrete where early age strength is desirable. To overcome this problem Micro silica is employed with GGBS in ternary concrete and it increases early strength of concrete by formation of secondary C-S-H gel at early stages due to fat pozzolanic reaction. The synergic effect of CRMs in ternary blend cement system enhances mechanical properties as well as make the resultant concrete durable (Mullic 2007).[3] It is well documented the use of fly ash along with ggbs in concrete results in a significant improvement in the mechanical properties of concrete, but researchers are yet to arrive at a unique conclusion regarding the use of GGBS along with micro silica. The present investigation was aimed to determine the combined influence of Micro silica and GGBS on the compressive strength of ternary concrete. 


\section{Literature Survey}

A.Oner, S.Akyuz [4] conducted an experimental study on optimum usage of GGBS for the compressive strength of concrete, and proved that the compressive strength of concrete mixtures containing GGBS increases as the amount of GGBS increase. They found that the addition of GGBS beyond 55\% of total binder content does not improve the compressive strength. This is due to presence of un reacted GGBS, acting as a filler material in the paste. Muhammad , Rizwan, Akram [5] Reported and describes the aim of research which was to evaluate the performance of OPC containing cement replacement materials in both binary and ternary system In this test variables different \%of GGBS and MS are using as supplementary cementious materials (SCM) . OPC was replaced with Micro Silica (SF) up to $7.5 \%$ and GGBS up to a level of $50 \%$. The compressive strength of all the mixes was performed at 3, 7,21, 28, and on 56 days duration. The use of SCM in the concrete mixes produced a lower strength value at the early age and gain in strength after 56 days. It was conclude from research data that, the gain in strength after 56 days is well pronounced for Mix A having 100\% OPC is greater. Surekha T; Dr. Chandrasekhar A[6] was investigating the strength properties of GGBS \& MS along with Polyvinyl Chloride (PVC) dust at the various replacement levels in M40 grade of concrete. A constant $8 \%$ of Micro Silica was used as on cement replacement for all the mix. Effect of GGBS was studied by replacing cement by 30 to $50 \%$ along with PVC dust 0 to $10 \%$ as additive. Mechanical Strengths such as compressive, Split Tensile \& Flexural strength are investigated. This has made the researchers to use supplementary cementing material in making concrete. Compressive strength of MS with GGBS and without PVC dust was achieved more strength than the control Mix. The higher strength was gained up to $40 \%$ of cement replacement with GGBS than the normal concrete and then after strength decreases. There is a decrease in workability with constant $8 \%$ MS \& increase Replacement level of GGBS (30\% to 50\%) and with $0 \%$ to $10 \%$ of PVC Dust. Sowmya.S.M; Premanand Kumar; Amar.R[7] In this Experimental study Mineral admixtures such as GGBS, MS and Fly ash are commonly used in concrete because they improve durability and reduce porosity as well as improve the interface with the aggregate the experimental work is carried out to investigate the optimum percentage of GGBS and MS to replace cement effectively. An attempt is made to replace cement with GGBS with an interval of $10 \%$ and SF by constant proportion for minimum grade concrete i.e., M20 and is tested for fresh and hardened properties to identify the optimum percentage of GGBS and silica fume in concrete. Workability has increased with the addition of GGBS. If further decreases with increase in percentage of GGBS. Split tensile strength will increased up to certain percentage with the addition of GGBS and it further decreases with increase of GGBS content in concrete. D.Audinarayana, P.sarika, Dr.Seshadri Sekhar.T, Dr.Srinivasa Rao, and Dr P Sravana G.Apparao [8] Investigated on the optimization of a Ternary Blended Cementitious system based on Ordinary Portland Cement (OPC)/ Fly Ash / Micro Silica for the development of high- performance concrete. Compressive Strength of Ternary Blended Concrete at the ages of 28, 90, 180 days for various combinations of Fly Ash and Micro Silica mixes were investigated. Fly Ash was replaced by $0 \%$, $15 \%$ and $20 \%$ along with Micro Silica of $0 \%, 5 \%$, and $10 \%$. All the mixes were studied at three water cement ratios of $0.55,0.45$ and 0.35 . When Fly Ash and Micro Silica are used in combination the beneficial effect of Fly Ash on fluidity can be used to compensate for the loss of workability with Micro Silica addition. The trend was reversed when the Micro Silica content increased from 5\% to 10\% for the same Fly Ash percentage (15\%).For water to binder ratios the combination of 5\% Micro Silica $+20 \%$ Fly Ash exhibited the least super plasticizer dosage while the mix 10\% Micro Silica $+15 \%$ Fly Ash. The combination of 5\% Micro Silica $+20 \%$ Fly Ash required the least dosage of superplasticiser for all the three W/B ratios studied. The combination of 5\% Micro Silica $+15 \%$ Fly Ash performed the best at all ages and at all the Water cement ratios studied in terms of Compressive Strength among the four combinations. The combination of 10\% Micro Silica $+20 \%$ Fly Ash gave the least Compressive Strength among the ternary mixes at all ages and at all Water cement ratio. K. Suvarna Latha, M V Seshagiri Rao, Srinivasa Reddy. V[9] made an effort to quantify the strength of ground granulated blast furnace slag (GGBS) and high volume fly ash (HVFA) at the various replacement levels and evaluates their efficiencies in concrete. The present study reports the results of an experimental study, conducted to evaluate the strengths and strength efficiency factors of hardened concrete, by partially replacing the cement by various percentages of ground granulated blast furnace slag and high volume fly ash for M20, M40 and M60 grades of concrete at different ages The partial replacement of cement with GGBS and HVFA in concrete mixes has shown enhanced performance in terms of strength and durability in all grades. This is due to the presence of reactive silica in GGBS and HVFA which offers good compatibility.A.K. Mullick[10] Describes the characteristics of cementitious systems required to meet the diverse requirements of strength and durability of concrete and highlights the advantages of part replacement of OPC by fly ash, GGBS and MS - either singly or in combination in ternary blends. Examples of successful application are cited. With favorable raw materials in judicious raw mix design and due control in plant operations, it is possible to produce OPC having all the desirable characteristics to make concrete durable under different conditions of exposure during its service life. TBC of OPC with Micro silica and fly ash or GGBS are particularly useful to render greater durability to 
concrete. C M Dordi, AN N Vyasa Rao and Manu[11] Reported that the results indicate that MFGGBS addition in concrete improves cohesiveness, workability and workability retention in fresh state. The long term strength and permeability characteristics are also favorable. To have accrued benefits with MFGGBS, mix proportion is redesigned and trials are carried out to establish MFGGBS as a preferred additive for high performance fly ash based concretes. Use of fine and micro fine mineral additives in high performance concrete is a must to have improved characteristics both in fresh and hardened states.

\section{Research Objective}

To determine combined influence of Micro silica and GGBS on compressive strength of Ternary concrete. To determine the optimum ternary concrete mix by adding Mineral admixtures (M.S \& GGBS).

To utilize Industrial by products and find out the economical and performance evaluation of concrete mix. To create healthy environment world-wide by using industrial by products wisely.

\section{Research Significance}

In the recent and past, investigators attempted to enhance the strength properties of binary, ternary and quarternary concrete by using different types of mineral admixtures (MA) with different combinations. Though enhancement in the strength properties of ternary blended concrete through mineral admixtures like Fly ash, metakaolin, etc., but there exists little understanding of Micro silica and GGBS combinations and the information is still scanty. The contribution of silica fume to the strength of concrete is yet to be fully quantified. Therefore the present investigation is a step in this direction.

\section{Experimental Program}

The experimental program was planned to produce Ternary Blended Concrete with reduced cement content by adding different percentages of Micro Silica and GGBS. Procedure for blending, mixing, casting and curing of specimens are shown in Fig1 to Fig.6.Three groups of each consists of 36 ternary (OPC+MS+GGBS) blended concrete cubes of $150 \mathrm{~mm}$ size were casted by replacing OPC with $20 \%, 30 \%, 40 \%$, and $50 \%$ of GGBS with 5\%, $10 \%$ and $15 \%$ of Micro silica as constant in each group. Also 9 cubes were casted for control concrete with $100 \%$ of ordinary Portland cement. A Total of 117 cubes were casted for each water-cement ratio. All the specimens were cured by immersion. Three specimens of ternary concrete and control concrete were tested for saturated surface dry state to obtain their compressive at 7, 28 and 90 days of curing.

\subsection{Materials}

5.1.1 Cement: Ordinary Portland cement (OPC), 53 grade confirming to BIS 12269-1987(specific gravity: 3.16, Blaine fineness: $320 \mathrm{~m}^{2} \cdot / \mathrm{kg}$ )

5.1.2 Micro Silica: Micro Silica -920D [12] as a mineral admixture in dry dandified form was obtained from "ELKEM South Asia (P) Ltd., Navi Mumbai confirming to ATSM-C (1240-2000) having specific gravity

2.2 and fineness $20000 \mathrm{~m}^{2} / \mathrm{kg}$.

5.1.3 GGBS: GGBFS was collected from JSW-HYD [13]. Confirming to IS: 12089 - 1987. (Specific gravity: 2.87 Fineness: $\mathrm{m}^{2} / \mathrm{kg}$.)

5.1.4 Fine Aggregate: Locally available river sand confirming to zone II of table 4 of BIS: 383-1970 (specific gravity: 2.6 and fineness modulus 3.17 and bulk density $1793 \mathrm{~kg} / \mathrm{m}^{3}$ ) was used as fine aggregate.

5.1.5 Coarse Aggregate: Locally available quarried and crushed granite stones confirming to graded aggregate of nominal size between $20 \mathrm{~mm}$ and $4.75 \mathrm{~mm}$ as per table 2 of BIS:383-1970 (specific gravity: 2.9, fineness Modulus: 6.87 , bulk density: $1603 \mathrm{~kg} / \mathrm{m}^{3}$ )

5.1.6 Water: Clean drinking water available in the college campus was used for mixing and curing of concrete confirming to IS 456-2000.

5.1.7 Super Plasticizers: Chemical admixture based on Sulphonated Naphthalene Formaldehyde condensateCONPLAST SP 430 [14] confirming to BIS 9103-1999 and ASTM C-494.

\subsection{Mix Proportions}

5.2.1 Ordinary concrete: Mix design is carried out as per guide line given in IS: 10262-2009, which yielded mix proportions of 1:2.42:3.37, 1.1.98:2.76 and 1:1.52:2.11 for water cement ratios of $0.55,0.45$ and 0.35 respectively. Total of 27 cubes were made as reference mix. To enhance workability a sulphonated naphthalene formaldehyde super plasticizer (SP430) was used at a dosage of 1 litre/100kg by weight of cement. The composition of ordinary concrete is given in Table 1 . 
Table 1: Mix proportions and Quantity of material required for ordinary concrete $\left(\mathrm{kg} / \mathrm{m}^{3}\right)$

\begin{tabular}{|l|l|l|l|l|l|}
\hline Water -Cement Ratio & Cement $(\mathrm{kg})$ & $\begin{array}{l}\text { Water } \\
\text { (litres) }\end{array}$ & FA(kg) & CA(kg) & SP (litres) \\
\hline \multirow{2}{*}{ W/C $=0.55$} & 324 & 178 & 785 & 1093 & 0 \\
\cline { 2 - 6 } & 1 & 0.55 & 2.4 & 3.373 & 0 \\
\hline \multirow{2}{*}{ W/C $=0.45$} & 387 & 174 & 768 & 1068 & \multirow{2}{*}{3.87} \\
\cline { 2 - 5 } & 1 & 0.45 & 1.98 & 2.76 & \\
\hline \multirow{2}{*}{ W/C $=0.35$} & 486 & 170 & 738 & 1027 & \multirow{2}{*}{4.86} \\
\cline { 2 - 5 } & 1 & 0.35 & 1.52 & 2.11 & \\
\hline
\end{tabular}

5.2.2 Ternary concrete mixes: Twelve Ternary Mixes (OPC + Micro Silica + GGBS) were made with cement replacement. 324 cubes were prepared for all water-cement ratios. All the Ternary mixes were prepared with super plasticizer at a dosage of approximately 1.0 liter/100 kg of cement. The compositions of Ternary concretes are given in Table 2.

Table 2: Mix proportions and Quantity of material required for Ternary Concrete $\left(\mathrm{kg} / \mathrm{m}^{3}\right)$

\begin{tabular}{|c|c|c|c|c|c|c|c|c|c|c|c|c|c|c|c|c|c|c|c|c|c|}
\hline \multirow[b]{2}{*}{ Nix Id } & \multirow{2}{*}{$\begin{array}{l}\text { Temary concrete (TC) } \\
(\mathrm{C} \%+\mathrm{MS} \%+\mathrm{GGBS} \%)\end{array}$} & \multicolumn{6}{|c|}{$W C=0.55$} & \multicolumn{7}{|c|}{$W C=0.45$} & \multicolumn{7}{|c|}{$W C=0.35$} \\
\hline & & Cement & MS & GGBS & $\mathrm{FA}$ & $\mathrm{CA}$ & Water & Cement & MS & GGBS & $\mathrm{FA}$ & $\mathrm{CA}$ & Water & SP & $\begin{array}{c}\text { Cemen } \\
t\end{array}$ & MS & GGBS & FA & $\mathrm{CA}$ & Whater & SP \\
\hline $\mathrm{CM}$ & $100 \%$ & 324 & 0 & 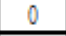 & 785 & 1093 & 178 & 387 & 0 & 0 & 768 & 1068 & 174 & 3.87 & 486 & 0 & 0 & 738 & 1027 & 170 & 4.86 \\
\hline TM1 & $20 \%$ & 243 & 162 & 64.8 & 785 & 1093 & 178 & 29025 & 19 & \begin{tabular}{|l|}
77.4 \\
\end{tabular} & 768 & 1068 & 174 & 3.87 & 364.5 & 243 & 972 & \begin{tabular}{|l|}
738 \\
\end{tabular} & 1027 & 170 & 4.86 \\
\hline TM2 & $60+5 \%+3$ & 2106 & 162 & 972 & 785 & 1093 & 178 & 25155 & 19 & 1161 & 768 & 1068 & 174 & 3.87 & 3159 & 243 & 145.8 & 738 & 1027 & 170 & 4.86 \\
\hline TM3 & $3 \%$ & 1782 & 162 & 129.6 & 785 & 1093 & 178 & 21285 & 19 & 1548 & 768 & 1068 & 174 & 3.87 & 2673 & 243 & 194.4 & 738 & 1027 & 170 & 4.86 \\
\hline TM4 & $0 \%$ & 145.8 & 162 & 162 & 785 & 1093 & 178 & 174.15 & 19 & 193.5 & 768 & 1068 & 174 & 3.87 & 218.7 & 243 & 243 & 738 & 1027 & 170 & 4.86 \\
\hline TM5 & 70 & 2268 & 324 & 64.8 & 785 & 1093 & 178 & 270.9 & 39 & 77.4 & 768 & 1068 & 174 & 3.87 & 340.2 & 486 & 972 & 738 & 1027 & 170 & 4.86 \\
\hline TM6 & $60 \%+10 \%+30 \%$ & 1944 & 324 & 97.2 & 785 & 1093 & 178 & 2322 & 39 & 1161 & 768 & 1068 & 174 & 3.87 & 291.6 & 486 & 145.8 & 738 & 1027 & 170 & 4.86 \\
\hline TM7 & $50 \%+1$ & 162 & 324 & 129.6 & 785 & 1093 & 178 & 193.5 & 39 & 1548 & 768 & 1068 & 174 & 3.87 & 243 & 486 & 194.4 & 738 & 1027 & 170 & 4.86 \\
\hline TM8 & $40 \%+10 \%+50 \%$ & 129.6 & 324 & 162 & 785 & 1093 & 178 & 154.8 & 39 & \begin{tabular}{|l|l|}
193.5 \\
\end{tabular} & 768 & 1068 & 174 & \begin{tabular}{|l|l|} 
\\
\end{tabular} & 194.4 & 486 & 243 & 738 & 1027 & 170 & 4.86 \\
\hline TM9 & $65 \%+15 \%+20 \%$ & 2106 & 486 & 64.8 & 785 & 1093 & 178 & 25155 & 58 & \begin{tabular}{|l|}
77.4 \\
\end{tabular} & 768 & 1068 & 174 & 3.87 & 3159 & 729 & 972 & 738 & 1027 & 170 & 4.86 \\
\hline TM10 & $6+370 \%$ & 1782 & 486 & 972 & 785 & 1093 & 178 & 21285 & 58 & 1161 & 768 & 1068 & 174 & 3.87 & 2673 & 729 & 145.8 & 738 & 1027 & 170 & 4.86 \\
\hline TM11 & $45 \%+15 \%+40 \%$ & 145.8 & 48.6 & 129.6 & 785 & 1093 & 178 & 174.15 & 58 & 1548 & 768 & 1068 & 174 & 3.87 & 218.7 & 729 & 194.4 & 738 & 1027 & 170 & 4.86 \\
\hline TM12 & $35 \%+15 \%+50 \%$ & 113.4 & 486 & 162 & 785 & 1093 & 178 & 135.45 & 58 & 193.5 & 768 & 1068 & 174 & 3.87 & 170.1 & 729 & 243 & 738 & 1027 & 170 & 4.86 \\
\hline
\end{tabular}

\subsection{Mixing, Casting, Curing, and Testing of Specimens.}

5.3.1Mixing: Mixing was done manually on smooth concrete pavement. Micro silica and GGBS were first blended in the required percentage and subsequently, blended with OPC at the required proportions before mixing with the fine aggregate and coarse aggregate mix in dry condition. Water was then added gradually and the entire heap was mixed thoroughly to ensure homogeneity and to obtain cohesive concrete.5.3.2 Casting: Standard cast iron metal moulds were used for casting the cubes. The moulds have been cleaned of dust particles and applied with mineral oil on all sides before concrete is poured into the mould. Thoroughly mixed concrete was placed layer by layer to cast the specimens. The specimens were prepared both by hand compaction as well by imparting vibrating through vibrating table. The specimens were finished smooth and kept under wet gunny bags for 24 hours. Whole casting procedure is confined to Indian Standard: 10086-1882. Total of 351 (27 for $\mathrm{CC}$ and 324 for TC) cubes were casted to determine compressive strength.

5.3.3 Curing: After casting, the moulded specimens are stored in the laboratory free from vibration, in moist air and at room temperature for 24 hours. After this period, the specimens are removed from the moulds and immediately submerged in the clean fresh water of curing tank. The curing water is removed after every 5 days. The specimens are cured for 7, 28 and 90 days.

\subsection{Testing of Specimens}

At the age of 7, 28 and 90 days, the specimens were taken out of water and allowed to dry under shade and then tested for compressive strengths at room temperature..The strength was determined on three specimens as per Indian Standard: 516-1959.from each mixture, 5.4.1 Compressive strength: Cube compression tests were performed on standard cubes of size $150 \times 150 \times 150 \mathrm{~mm}$ after 7, 28 and 90 days curing as per IS:516-1959 [15]. as shown in Fig.6 and the test results are presented in Table 3

Compressive strength of specimen was calculated by the expression:

$f_{c u}=P_{c} / A$

\section{Where,}

$P_{c}=$ Failure load in compression, $\mathrm{kN}$

$A=$ Loaded area of cube, $\mathrm{mm}^{2}$ 


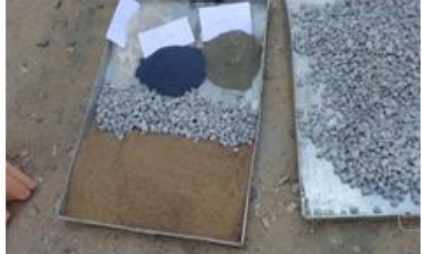

Fig.1 Aggregates and Admixtures. Fig.2 Blending of SCMs.

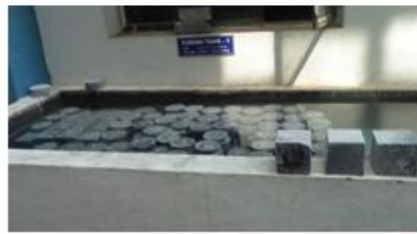

Fig.4 Curing
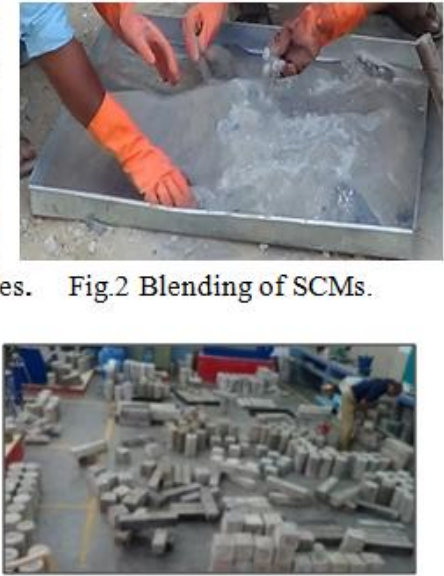

Fig.5 Concrete Lab

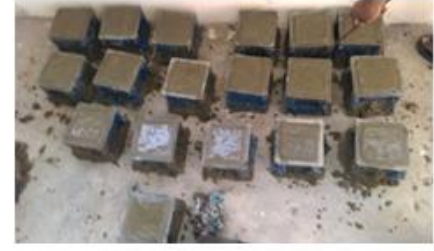

Fig.3 Casting

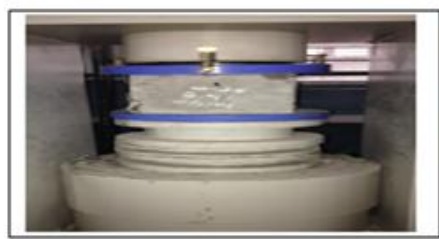

Fig.6. Compression test

Table 3: Compressive Strength gain of Ternary Concrete over Ordinary concrete

\begin{tabular}{|c|c|c|c|c|c|c|c|c|c|c|}
\hline \multirow[t]{2}{*}{ Mix Id } & \multirow{2}{*}{$\begin{array}{l}\text { Ternary concrete (TC) } \\
(\mathrm{C} \%+\mathrm{MS} \%+\mathrm{GGBS} \%)\end{array}$} & \multicolumn{3}{|c|}{$\mathrm{W} / \mathrm{C}=0.55$} & \multicolumn{3}{|c|}{$\mathrm{W} / \mathrm{C}=0.45$} & \multicolumn{3}{|c|}{$\mathrm{W} / \mathrm{C}=0.35$} \\
\hline & & $\begin{array}{l}7 \\
\text { Days }\end{array}$ & $\begin{array}{l}28 \\
\text { Days }\end{array}$ & $\begin{array}{l}90 \\
\text { Days }\end{array}$ & $\begin{array}{l}7 \\
\text { Days }\end{array}$ & $\begin{array}{l}28 \\
\text { Days }\end{array}$ & $\begin{array}{l}90 \\
\text { Days }\end{array}$ & $\begin{array}{l}7 \\
\text { Days }\end{array}$ & $\begin{array}{l}28 \\
\text { Days }\end{array}$ & $\begin{array}{l}90 \\
\text { Days }\end{array}$ \\
\hline $\mathrm{CM}^{\mathrm{a}}$ & $100 \%+0 \%+0 \%$ & 24.14 & 36.50 & 38.15 & 26.80 & 44.50 & 48.19 & 34.60 & 61.60 & 72.13 \\
\hline $\mathrm{TM}^{\mathrm{b}}$ & $75 \%+5 \%+20 \%$ & 23.33 & 38.11 & 40.50 & 26.09 & 47.60 & 52.54 & 33.82 & 67.17 & 79.40 \\
\hline TM2 & $65 \%+5 \%+30 \%$ & 23.20 & 40.32 & 43.78 & 26.00 & 51.89 & 58.94 & 33.68 & 73.83 & 88.72 \\
\hline TMB & $55 \%+5 \%+40 \%$ & 22.83 & 39.43 & 42.40 & 25.46 & 50.36 & 55.87 & 33.00 & 69.79 & 83.70 \\
\hline TM4 & $45 \%+5 \%+50 \%$ & 22.60 & 38.81 & 41.61 & 25.37 & 48.47 & 53.60 & 32.81 & 68.13 & 81.30 \\
\hline TM5 & $70 \%+10 \%+20 \%$ & 25.08 & 39.2 & 41.92 & 28.97 & 48.97 & 53.96 & 37.70 & 69.80 & 83.18 \\
\hline TM6 & $60 \%+10 \%+30 \%$ & 24.50 & 42.95 & 47.52 & 28.02 & 57.59 & 66.69 & 37.20 & 83.64 & 101.00 \\
\hline TM7 & $50 \%+10 \%+40 \%$ & 24.38 & 42.21 & 46.10 & 27.21 & 54.36 & 60.90 & 36.06 & 80.38 & 96.70 \\
\hline TM8 & $40 \%+10 \%+50 \%$ & 22.78 & 39.19 & 42.16 & 26.15 & 52.00 & 58.22 & 33.82 & 75.10 & 90.08 \\
\hline TM9 & $65 \%+15 \%+20 \%$ & 25.70 & 35.13 & 37.01 & 28.71 & 43.33 & 47.01 & 38.00 & 60.17 & 70.62 \\
\hline TM10 & $55 \%+15 \%+30 \%$ & 25.41 & 39.3 & 42.58 & 28.59 & 48.90 & 55.20 & 37.76 & 70.18 & 83.46 \\
\hline TM11 & $45 \%+15 \%+40 \%$ & 25.01 & 34.84 & 36.96 & 28.56 & 42.70 & 47.00 & 37.63 & 59.60 & 70.60 \\
\hline TM12 & $35 \%+15 \%+50 \%$ & 24.92 & 34.3 & 36.00 & 28.08 & 41.90 & 46.00 & 37.03 & 58.40 & 69.00 \\
\hline
\end{tabular}

a Control mix b Temary mix

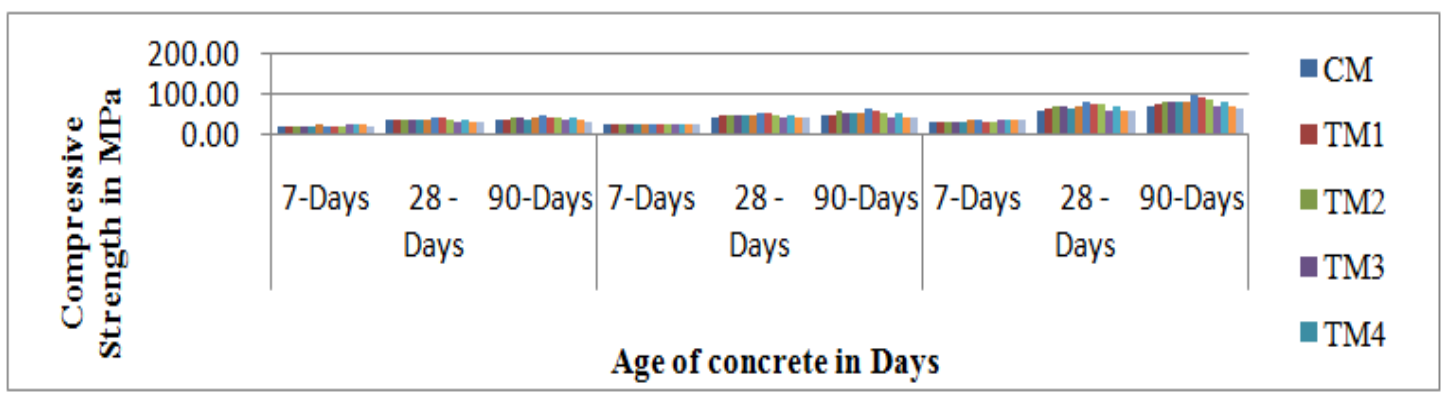

Fig.7: Compressive Strength of TBC w.r.t Normal Concrete MS (5\% 10\% and 15\%) GGBS (20\%-50\%)

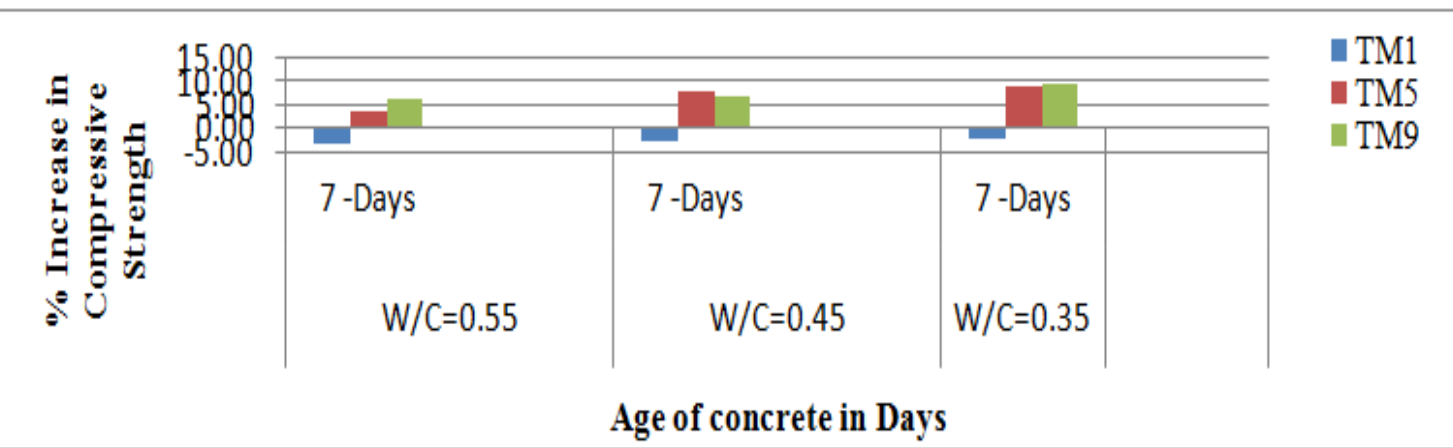

Fig.8: \% Increase in Compressive Strength of TBC w.r.t Ordinary Concrete among w/c ratios at 7 day curing 


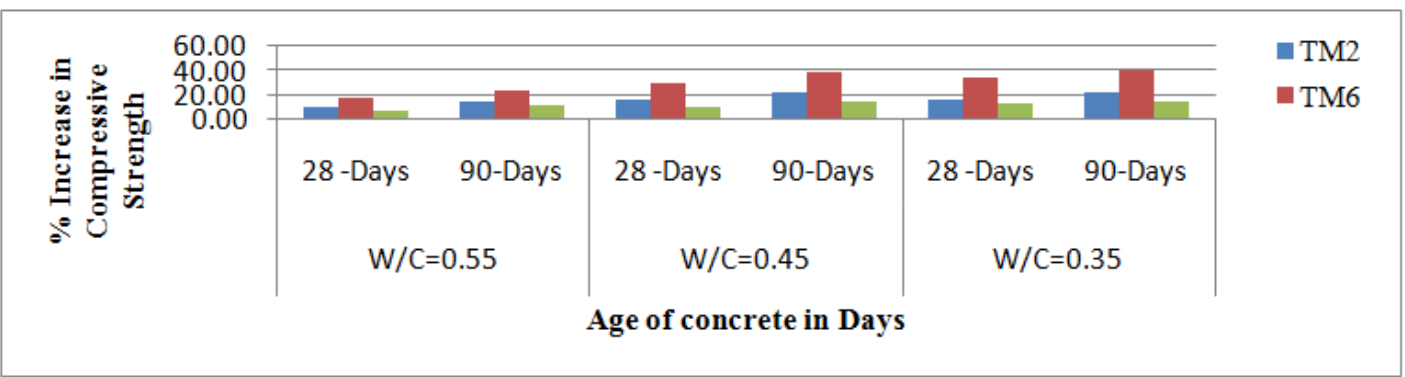

Fig.9: \% Increase in Compressive Strength of TBC w.r.t Ordinary Concrete among w/c ratios at 28 day curing

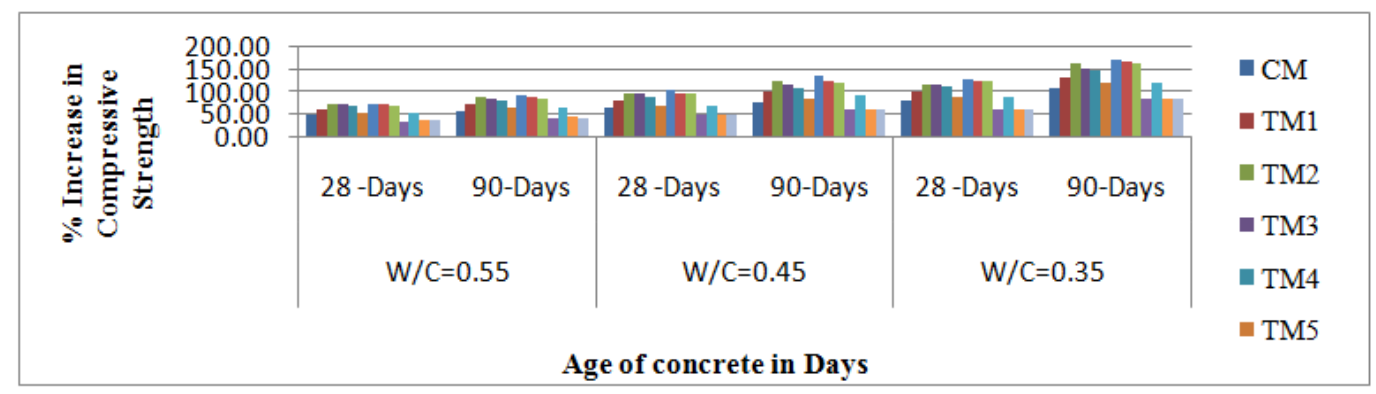

Fig.10: \% increase in Compressive Strength of TBC w.r.t to Ordinary Concrete at the age of 28 and 90 days with its 7 day strength

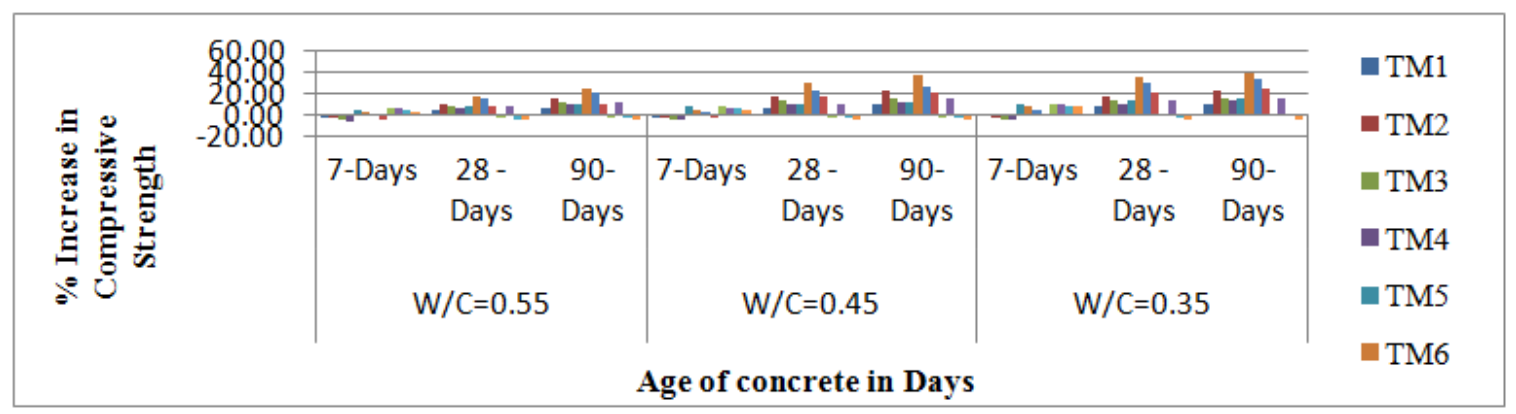

Fig.11 \% increase in Compressive Strength of TBC w.r.t Normal Concrete, MS (5\% 10\% and 15\%) and GGBS $(20 \%-50 \%)$

\subsection{Fresh Concrete properties:}

\section{Results And Discussion}

6.1.1 Mix Characteristics: While observing the characteristics of fresh concrete, Micro Silica and its super fine particles, causes the ternary mixtures to be sticky and cohesive, when compared to control concrete mixtures and also noticed that, the cohesiveness increases with increase in Micro Silica content and which leads to more paste volume, and contributes to a reduction in bleeding. All the Mixtures have exhibited satisfactory characteristics regarding bleeding and Segregation.

6.1.2 Workability: The workability test results of ordinary concrete and ternary mixes are measured from slump test. It is observed that, in the combination of GGBS and Micro silica, the beneficial effect of GGBS on fluidity can be used to compensate for the loss of workability due to Micro silica addition. Workability of ternary blended concrete increases gradually until GGBS content reaches to $30 \%$ with Micro silica (5\% to $10 \%)$ as constant, resulted in decreasing the dosage of super plasticizer and it indicates the positive influence of GGBS on the optimum super plasticizer dosage in the ternary mixers. But the trend was reversed, when Micro silica content increased from $10 \%$ to $15 \%$ for all percentage levels of GGBS. The combination of (MS $5 \%+$ GGBS30\%) exhibited the least super plasticizer dosage, while the combination (MS15\%+30\%) exhibited highest optimum super plasticizer dosage. Also observed that, the dosage of super plasticizer increases as waterbinder ratio decreases, it is due to the fact that more superplasticizer molecules required for adsorption on the surface of cement and mineral admixture particles. The optimum dosage was increased sharply as the water to binder ratio decreased from 0.55 to 0.45 and 0.35 . Super plasticizer was not required for control mix of water to binder ratio 0.55 . But it was required for water to binder ratios 0.45 and 0.35 to get medium workability.

International Conference on Recent Innovations in Civil \& Mechanical Engineering $53 \mid$ Page [i- CAM2K16] DOI: 10.9790/1684-16053014856 


\subsection{Hardened concrete properties}

Compressive of control concrete and ternary concrete mixtures were determined at 7, 28, and 90 days of curing. The average of three samples was taken for every testing age.

\subsubsection{Compressive strength development}

From the Table 3 it is observed that, the early age (7days) strength of ternary concrete varies with respect to the percentage levels of Micro silica (MS) and GGBS. Compressive strength of ternary concrete shows decreasing with increase of GGBS content at MS (5\%) as constant, and it increases slightly at MS (10\%). GGBS in the ternary concrete, which delays the early age strength due to slow pozzolanic reaction, is the reason for this phenomenon. But there is a considerable increase in compressive strength of Ternary concrete at MS $15 \%$ as constant, for all percentage levels of GGBS. Inclusion of Micro silica in cement system influenced the strength of ternary concrete at early stage significantly [16].Conversely it is observed that, the 28 day compressive strength of ternary concrete increases gradually until GGBS content reaches to $30 \%$ and there after it falls even increase of GGBS, with MS (5\% and 10\%) as constant. But it is noticed that, the strength of Ternary concrete is lower than that of control concrete with MS 15\% as constant. The same trend was observed even at 90 days curing irrespective of water to binder ratio

\subsubsection{Optimum Ternary Mix Combinations}

Table 3 shows that the maximum cube compressive strength (25.70MPa) was obtained by ternary mix TM9 $(65 \% \mathrm{OPC}+15 \% \mathrm{MS}+20 \% \mathrm{GGBS})$ at 7 day curing. And also observed that the ternary mix TM6 (60\% OPC $10 \% \mathrm{MS}+30 \% \mathrm{GGBS})$ attained maximum cube compressive strength (42.95MPa) at 28 days testing. Even at 90 days curing, the same combination i.e. TM6 shows maximum cube compressive strength (47.52MPa)

at water to binder ratio 0.55 For water to binder ratio 0.45 , the maximum cube compressive strength $(28.71 \mathrm{MPa})$ was obtained by ternary mix TM9 $(65 \% \mathrm{OPC}+15 \% \mathrm{MS}+20 \% \mathrm{GGBS})$ at 7 day curing. And also observed that the ternary mix TM6 (60\% OPC 10\%MS+30\%GGBS) attained maximum cube compressive strength (57.59MPa) at 28 days testing. Even at 90 days curing, the same combination i.e. TM6 shows maximum cube compressive strength $(66.69 \mathrm{MPa})$ For water to binder ratio 0.35 , the maximum cube compressive strength (38.0MPa) was obtained by ternary mix TM9 $(65 \% \mathrm{OPC}+15 \% \mathrm{MS}+20 \% \mathrm{GGBS})$ at 7 day curing. And also observed that the ternary mix TM6 (60\% OPC+10\%MS+30\%GGBS) attained maximum cube compressive strength (83.64MPa) at 28 days testing. Even at 90 days curing, the same combination i.e. TM6 shows maximum cube compressive strength (101.0MPa)

\subsubsection{Maximum Percentage gain in Compressive strength with respect to binder content}

The analysis of experimental data showed that, the addition of Micro silica and GGBS enhanced the strength properties of ternary mixtures, which was on par with that of control concrete mixtures.

The 7 days compressive strength of ternary mix (TM9) is 6.46\%, 7.13\% and 9.83\% higher than the controlled concrete mix for w/c ratios $0.55,0.45$ and 0.35 respectively.

The 28 day compressive strength of ternary mix (TM6) had 17.69\%, 29.42\% and 34.97\% higher than the controlled concrete mix for w/c ratios $0.55,0.45$ and 0.35 respectively.

The 90 day compressive strength of ternary mix (TM6) had $24.56 \%, 38.39 \%$ and $40.02 \%$ higher than the controlled concrete mix for w/c ratios $0.55,0.45$ and 0.35 respectively

\subsubsection{Maximum Percentage gain in Compressive strength with respect curing days}

The compressive strength of ternary mix (TM6) at 28 day curing, had $75.31 \%, 105.53 \%$ and $124.80 \%$ higher than that of 7 day curing for w/c $0.55 \mathrm{w} / \mathrm{c}, 0.45$ and w/c 0.35 respectively.

The compressive strength of ternary mix (TM6) at 90 day curing, had $93.96 \% 138.01 \%$ and $171.51 \%$ higher than that of 7 day curing for w/c $0.55 \mathrm{w} / \mathrm{c}, 0.45$ and w/c 0.35 respectively.

\subsubsection{Percentage gain in Compressive strength with respect water to binder ratio}

The maximum 28 day compressive strength of ternary mix (TM6) at w/c 0.45 and 0.35 had $34.03 \%$ and $94.73 \%$ higher than that of w/c 0.55 respectively and it had $40.34 \%$ and $112.68 \%$ at 90 day curing,

\section{Conclusions}

Extensive experimentation was carried out to determine the combined effect of Micro silica and GGBS on compressive, split tensile and flexural strengths of concrete at water-cement ratio 0.55 , and cement replacement of $0 \%$ to $65 \%$. The following conclusions can be derived from the present study.

1. The inclusion of Micro silica in concrete resulting in significant improvement in the early age strength of ternary concrete. The optimum 7 days strength has been obtained by $15 \%$ micro silica, but it is reduced to $10 \%$ at 28 day strength.

2. The early age strength of concrete with GGBS was lower than the control concrete. However, as the curing period is extended, the strength increases. The reason is that the pozzolanic reaction is slow and the formation of calcium hydroxide requires time. 
3. The strength properties of concrete increases as the GGBS content increased up to an optimum point. Therefore it can be concluded that, there is an optimum level for the efficient use of GGBS content, which yields the highest strength. The optimum level of GGBS content for maximizing strengths is at about $30 \%$ of total binder content.

4. Addition of GGBS in concrete, beyond 30\% does not improve the strength. And it can be concluded that, after certain limit, the GGBS, which could not enter into reaction, but behaves like fine aggregate. It indicates that, GGBS cannot be used efficiently as a binder, but rather as filler in the concrete.

5. The 7day compressive strength ternary concrete is maximum at 35\% replacement of OPC by MS and GGBS. and it is $6.46 \%$ higher than control concrete. Whereas 28 day and 90 day compressive strength is maximum at $30 \%$, it is $17.69 \%$ and 24.56 respectively. The percentage increase in compressive strength of ternary concrete is $75.31 \%$ and $93.96 \%$ when compared to 28 day strength

From the above investigation, an effective and efficient ternary concrete can produce by using mineral admixture (Micro silica and GGBS), in ternary blended concrete Micro silica acts filler and GGBS controls workability. Therefore, this combination is more effective in improving the properties of ternary blended concrete. It was observed that the combination of Micro silica and GGBS not only enhances the Compressive strengths but also many other beneficial properties like durability, better crack resistance, low permeability, cost effectiveness etc. therefore the Triple blended concrete is quite suitable for high performance concrete(HPC).

\section{Recommendations}

From the above cited test results, the authors recommending the use of Micro silica and GGBS in the ternary concrete mix TM6 (C60\%+MS10\%+GGBS30\%) to get economical and durable concrete.

\section{Acknowledgemnts}

Author is thankful to Elkem South Asia pvt.ltd. Mumbai and JSW Steel Pvt.Ltd.for providing material support for this research work.

\section{References}

[1] Malhotra, V.M. (2004), "Role of supplementary Cementing materials and super plasticizers in Reducing".

[2] BIS (2000), IS: 456-2000.Indian Standard for plain and reinforced concrete-Code of Practice, BIS, New Delhi.

[3] Mullick, A.K, Performance of Concrete with Binary and ternary cement blends. Indian Concrete Journal 81(1), 1522.

[4] A.Oner, S.Akyuz "An experimental study on optimum usage of GGBS for the compressive.

[5] Muhammad Rizwan Akram, "Effect of micro silica and ggbs on compressive strength and permeability of impervious concrete as a cement replacement 'European academic research vol. iii, issue 7/October2015 impact factor:3.4546 (uif)drii value:5.9( $b+$ ).

[6] Surekha T; Dr. Chandrashekhar A, "Experimental investigations on properties of concrete with silica fume, ggbs and pvc dust "international journal for research in applied science \& engineering technology (ijraset), volume 3, special issue-i1, june 2015 ic value: 13.98 issn:2321-9653

[7] Sowmya.S.M; Premanand Kumbar; Amar.R, "An experimental investigation on strength properties of concrete by replacing cement with ggbs and silica fume" international journal of research (ijr) vol-1, issue-8, September 2014 issn 2348-6848.

[8] D.Audinarayana, P.sarika, Dr.Seshadri Sekhar.T, Dr.Srinivasa Rao, Dr P Sravana G.Apparao,"Studies on compressive strength of ternary blended concretes at different water binder ratios" American journal of engineering research (ajer) 2013 (ajer) e-issn : 2320-0847 p-issn : 2320-0936 volume-02, issue-09, pp-37-45.

[9] K. Suvarna Latha, M V Seshagiri Rao, Srinivasa Reddy. V, "Estimation of ggbs and hvfa strength efficiencies in concrete with age," international journal of engineering and advanced technology (ijeat) ISSN: 2249 - 8958, volume2,issue-2, December 2012

[10] A.K. Mullick, "Performance of concrete with binary and ternary cement blends" January 2007 the Indian concrete journal.

[11] C M Dordi , A N Vyasa Rao and Manu Santhanam, " micro fine ground granulated blast furnace slag for high performance concrete" Third International Conference on Sustainable Construction Material and Technologies http://www.claisse.info/Proceedings.htm. 'Elkem South Asia'pvt.ltd.

[12] JSW Steel Pvt. Ltd, $7^{\text {th }}$ Floor, Surya Towers, 105,sardar patel Road, Kalasiguda, Secunderabad,Telangana -500003 www.fosroc.com

[13] BIS: 516-1959, Method of Tests for Strength of Concrete Bureau of Indian Standard, New Delhi. Kanchan Mals, A.K.Mullick, k.k. Jain and P.K.Singh "Effect of Relative Levels of Mineral Admixtures on Strength of Concrete with Ternary Cement Blend" International Journal of Concrete Structure and MaterialsVol.7, No.3.pp.239- 249, September 2013ISSN 1976-0485 
Mr.S.Vijaya Bhaskar Reddy, Professor and Head of Civil Engineering Department in CMR Technical

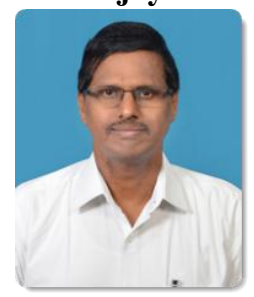
Campus, Hyderabad. Specialized in structural engineering having 18 years of academic experience and published 5 research papers. Research interests are Concrete Technology, Blended Concretes, Earth Quake Resistance Design of Structures, and Life Member of ISTE, Fellow Member of Institution of Engineering, Member Indian Society of Earth Quake Technology, Member Indian Concrete Institute.

Dr.P.Srinivasa Rao, Professor and Vice principal of Dept of Civil Engineering, J.N.T.U. College of DIIII) Engineering. Hyderabad, T.S. India.Specialized in structuralengineering. Research interests are Concrete Technology, Structural Design, High Performance Concrete Prefabricating Structures, Special Concretes and use of Micro Silica, Fly ash in Building Materials. He has been associated with a number of Design projects, for member of organizations and involved as a key person in Quality control and Mix Designs.Has 24 years of academic, research and industrial experience published over 100 research papers. He guided four Ph.Ds and 100 Match projects.Guiding $15 \mathrm{Ph} . \mathrm{Ds}$ students delivered invite lectures in other organizations and institutions.Member of ISTE, Member of ICI and Member of Institute of Engineers. 